\title{
Individual variation of the extent of milk fat depression in dairy ewes fed fish oil: Milk fatty acid profile and mRNA abundance of candidate genes involved in mammary lipogenesis
}

\author{
P. Frutos, ${ }^{1}$ P. G. Toral, and G. Hervás \\ Instituto de Ganadería de Montaña (CSIC-Universidad de León), Finca Marzanas s/n, 24346 Grulleros, León, Spain
}

\begin{abstract}
Dairy ewes are less prone than cows to milk fat depression (MFD) but suffer from this syndrome when marine lipids are added to their diet to modulate milk fatty acid (FA) profile. However, there are large individual differences in MFD extent, and the reasons behind this variability are uncertain. On this basis, a study was conducted in lactating sheep to test the hypotheses that individual susceptibility to the low-fat milk condition may be explained by differences in (1) the milk concentration of some FA, particularly antilipogenic FA, or (2) the transcriptional regulation of mammary lipogenesis. For $5 \mathrm{wk}, 15$ ewes received a total mixed ration supplemented with 0 (control; $\mathrm{n}=5$ ) or $20 \mathrm{~g}$ of fish oil/kg of dry matter [10 animals selected out of 22 and divided into those showing marked (RESPON + ; $=5$ ) or mild (RESPON-; $\mathrm{n}=5$ ) MFD]. Milk production and composition, including a comprehensive FA profile, were examined on 3 consecutive days before and after treatments. Candidate gene expression was also analyzed before the start of the trial and at its end using RNA isolated from milk somatic cells. According to the experimental design, the fish-oil-induced decrease in milk fat concentration was much stronger in RESPON+ $(-25.4 \%)$ than in RESPON- $(-7.7 \%)$. Milk from all ewes fed the supplemented diet showed rather uniform changes in the proportion of potentially healthy FA (such as cis-9,trans-11 18:2, trans-11 18:1, or 20:5n-3) and of those with confirmed or putative antilipogenic effects (e.g., cis-9 16:1, trans-10 and cis-11 18:1, trans-9,cis-11 18:2, and 10-oxo-18:0), without significant variation between RESPON+ and RESPON-. It was not possible to relate the very few exceptions to this general trend (e.g., in cis-7 16:1 and 22:6n-3) to responsiveness. Major mechanisms involved in mammary lipogenesis, specifically the uptake and de novo synthesis of FA, appeared to be unequally inhibited in
\end{abstract}

Received June 19, 2017.

Accepted August 19, 2017.

${ }^{1}$ Corresponding author: p.frutos@csic.es ewes displaying different degrees of MFD, with molar yields of $>16 \mathrm{C}$ FA being unaffected in RESPON-. However, this was not reflected in candidate gene expression. Supplementation with fish oil showed a tendency to lower the mRNA abundance of lipogenic genes such as ACSS2, FASN, LPIN1, FADS2, and INSIG1, but only $S C D$ and GPAT4 tended to differ between RESPON - and RESPON+. Overall, these results offer no convincing support for the initial hypotheses, so further research must be pursued to explain the individual variation in MFD severity.

Key words: antilipogenic fatty acid, gene expression, marine lipid, nutrigenomics, sheep

\section{INTRODUCTION}

Bauman et al. (2011) stated that the basis for dietinduced milk fat depression (MFD) had perplexed scientists for over a century. This perplexity continues today and extends not only to cows but also to small ruminants (Carreño et al., 2016; Toral et al., 2017). For several years, dairy sheep were considered to be less prone to diet-induced MFD (Shingfield et al., 2010), but their susceptibility to dietary addition of marine lipids or trans-10, cis-12 CLA has now been demonstrated (Capper et al., 2007; Hussein et al., 2013; Toral et al., 2015).

We have conducted several studies in ewes fed marine lipids rich in n-3 PUFA (e.g., Bichi et al., 2013; Carreño et al., 2016; Toral et al., 2015, 2016a, 2017) with the primary goal of modulating milk composition toward a healthier fatty acid (FA) profile. To some extent, we were also interested in the mechanism underlying the low-fat milk syndrome induced by marine lipids. Because most ovine milk is destined for cheese manufacturing (Haenlein, 2007), feeding these supplements may be challenging under practical conditions due to economic losses associated with MFD. Remarkably, we always observed individual differences in the responsiveness to marine lipids. For example, decreases in milk fat concentration ranged from 17 to $28 \%$ in ewes fed $0.8 \%$ marine algae (Bichi et al., 2013), from 14 to 
$32 \%$ in animals that consumed $1.7 \%$ fish oil (Carreño et al., 2016), or from 4 to $33 \%$ with diets supplemented with $2 \%$ fish oil (Toral et al., 2016a).

Individual variability might also explain some inconsistencies found in the literature about consumption of marine lipids and MFD in sheep. For instance, Capper et al. (2007) reported a clear fish-oil-induced MFD, whereas others show no effects or only a mild MFD. The latter include several trials conducted by Reynolds et al. (2006) in dairy ewes receiving a supplement consisting of a mixture of soybean and marine algae oils (4\%; $2: 1 \mathrm{wt} / \mathrm{wt}$, respectively). Their findings related to milk fat percentage contain increases, no significant differences, or a tendency toward mild MFD ( $-13 \%)$ with corn silages as the basal forage. Papadopoulos et al. (2002) found no significant variations in milk fat when n-3 PUFA-rich marine algae were added to the diet at concentrations of 2.4 or $4.7 \%$. Mozzon et al. (2002) and Tsiplakou and Zervas (2013) also reported no effect or slight but not significant decreases in milk fat concentration with fish oil supplementation. Cows have also been shown to display very different degrees of diet-induced MFD (Weimer et al., 2010).

On this basis, we conducted an experiment with dairy ewes fed fish oil to try to elucidate the reasons behind the individual variation in MFD extent, and we posed 2 hypotheses for testing. The first was that differences in the milk concentration of some FA, particularly potentially antilipogenic FA, may account for that individual variability. It is widely accepted that MFD is related to an inhibition of mammary lipogenesis by active biohydrogenation $(\mathbf{B H})$ intermediates that are produced under certain feeding conditions that alter rumen function (Bauman and Griinari, 2001). Although only trans10, cis-12 CLA has been unequivocally demonstrated to exert antilipogenic effects, some other BH metabolites have more recently been suggested to be able to impair milk fat synthesis (Shingfield et al., 2010; Bauman et al., 2011).

The second hypothesis was that differences in the transcriptional regulation of mammary lipogenesis would be responsible for individual variations in the susceptibility to MFD. Both hypotheses may be linked because it has been proposed that alterations, particularly downregulation, in the expression of genes involved in milk fat synthesis may be mediated by dietary nutrients, including some FA with antilipogenic characteristics (Harvatine and Bauman, 2006; Bionaz et al., 2015; Toral et al., 2017).

\section{MATERIALS AND METHODS}

All experimental procedures were approved and completed in accordance with Spanish and European Union regulations [R.D. 53/2013 (BOE, 2013), and Council Directive 2010/63/EU (EU, 2010)] for the protection of animals used for experimental purposes.

\section{Animals, Experimental Diets, and Management}

Fifteen lactating Assaf ewes $(\mathrm{BW}=76.4 \pm 2.66 \mathrm{~kg}$; $\mathrm{DIM}=48 \pm 1.4$; parity $=2.4 \pm 0.42$; milk yield $=$ $2.8 \pm 0.15 \mathrm{~kg} / \mathrm{d}$; means $\pm \mathrm{SE}$ ) were used in this study. They were selected from a total of 27 animals housed in individual tie stalls and randomly allocated to 1 of 2 diets: a TMR based on alfalfa hay (particle size $>4 \mathrm{~cm}$ ) and concentrates (50:50) without lipid supplementation (control group; $\mathrm{n}=5$ ) or supplemented with $20 \mathrm{~g}$ of fish oil (Afampes 121 DHA, Afamsa, Mos, Spain)/kg of diet DM (MFD group; $n=22$ ). The ingredients of the experimental diets, which were prepared weekly and included molasses to reduce selection of components, are shown in Table 1. All ewes were fed the control diet for a 3-wk adaptation period, and then both experimental diets for 5 more weeks, which allowed achievement of a stable MFD. At the end of this latter period, 10 ewes out of the 22 in the MFD group were selected to represent those showing a marked response in terms of MFD (RESPON+; $\mathrm{n}=5$ ) or just a mild response (RESPON-; $\mathrm{n}=5$ ) to the dietary addition of fish oil. The selection was carried out on the basis of decreases in milk fat concentration and differences between the 3 groups are shown in Table 2.

Ewes were milked twice daily at approximately 0830 and $1830 \mathrm{~h}$ in a single-side milking parlor with 10 stalls (DeLaval, Madrid, Spain). The diets were offered daily ad libitum after the morning milking, and clean water was always available.

\section{Measurements and Sampling Procedures}

Diets. Representative samples of the experimental diets were collected weekly and stored at $-30^{\circ} \mathrm{C}$ until analysis. Feed intake was individually measured 4 times a week by weighing the amounts of DM offered and refused by each animal.

Milk. At the end of the adaptation period ( $\mathrm{d}-5,-4$, and -3$)$ and after 31,32 , and $33 \mathrm{~d}$ on treatments, milk yield was recorded and individual milk samples were collected and composited according to morning and evening milk yields. One aliquot of composite milk was preserved with bronopol (D\&F Control Systems Inc., San Ramon, CA) and stored at $4^{\circ} \mathrm{C}$ until analysis for fat, CP, and TS concentrations. Milk FA composition was determined in untreated samples stored at $-30^{\circ} \mathrm{C}$ until analysis.

Milk Somatic Cells. Total RNA was isolated from milk somatic cells, which has been shown to re- 
Table 1. Formulation and chemical composition of the TMR without lipid supplementation (control diet) or supplemented with $2 \%$ DM of fish oil

\begin{tabular}{|c|c|c|}
\hline \multirow[b]{2}{*}{ Item } & \multicolumn{2}{|c|}{ Diet } \\
\hline & Control & Supplemented \\
\hline \multicolumn{3}{|l|}{ Ingredient, $\mathrm{g} / \mathrm{kg}$ of fresh matter } \\
\hline Dehydrated alfalfa hay, particle size $>4 \mathrm{~cm}$ & 500 & 491 \\
\hline Whole corn grain & 140 & 138 \\
\hline Whole barley grain & 100 & 98 \\
\hline Soybean meal solvent $440 \mathrm{~g}$ of $\mathrm{CP} / \mathrm{kg}$ & 150 & 147 \\
\hline Sugar beet pulp, pellets & 50 & 49 \\
\hline Molasses, liquid & 40 & 39 \\
\hline Fish oil $^{1}$ & 0 & 18 \\
\hline Vitamin-mineral supplement $^{2}$ & 20 & 20 \\
\hline \multicolumn{3}{|l|}{ Chemical composition, $\mathrm{g} / \mathrm{kg}$ of DM } \\
\hline OM & 887 & 893 \\
\hline $\mathrm{CP}$ & 180 & 179 \\
\hline NDF & 315 & 315 \\
\hline $\mathrm{ADF}$ & 220 & 219 \\
\hline Starch & 137 & 139 \\
\hline Total FA & 19.9 & 38.5 \\
\hline 14:0 & 0.11 & 0.82 \\
\hline $16: 0$ & 4.32 & 7.87 \\
\hline cis-9 16:1 & 0.05 & 0.88 \\
\hline $18: 0$ & 0.76 & 1.73 \\
\hline cis-9 18:1 & 2.56 & 5.49 \\
\hline cis-11 18:1 & 0.19 & 0.75 \\
\hline $18: 2 n-6$ & 7.74 & 8.03 \\
\hline $18: 3 n-3$ & 3.18 & 3.26 \\
\hline $20: 5 n-3$ & 0.00 & 1.25 \\
\hline $22: 5 n-3$ & 0.00 & 0.29 \\
\hline $22: 6 n-3$ & 0.00 & 3.87 \\
\hline
\end{tabular}

${ }^{1}$ Semirefined tuna and sardine oil (Afampes 121 DHA; Afamsa, Mos, Spain); contained $[\mathrm{g} / \mathrm{kg}$ of total fatty acid (FA)]: 14:0 (37), 16:0 (191), cis-9 16:1 (44), 17:0 (9), 18:0 (52), cis-9 18:1 (157), cis-11 18:1 (30), 18:2n-6 (23), 18:3n-3 (8), cis-11 20:1 (18), 20:5n-3 (66), 22:5n-6 (13), 22:5n-3 (15), and 22:6n-3 (204).

${ }^{2}$ Macrofac Rumiantes (UP911755130; DSM Nutritional Products S.A., Madrid, Spain). Declared as containing: Ca $(285 \mathrm{~g} / \mathrm{kg}), \mathrm{Na}(7.5 \mathrm{~g} / \mathrm{kg}), \mathrm{Fe}(3 \mathrm{~g} / \mathrm{kg}), \mathrm{Mn}(3 \mathrm{~g} / \mathrm{kg}), \mathrm{Zn}(2 \mathrm{~g} / \mathrm{kg}), \mathrm{Mg}(1 \mathrm{~g} / \mathrm{kg}), \mathrm{P}(910 \mathrm{mg} / \mathrm{kg})$, Mo (100 $\mathrm{mg} / \mathrm{kg}), \mathrm{Co}(67 \mathrm{mg} / \mathrm{kg}), \mathrm{I}(50 \mathrm{mg} / \mathrm{kg}), \mathrm{S}(40 \mathrm{mg} / \mathrm{kg})$, Se $(7 \mathrm{mg} / \mathrm{kg})$, vitamin A $(200,000 \mathrm{IU} / \mathrm{kg})$, vitamin $\mathrm{D}_{3}$ $(40,000 \mathrm{IU} / \mathrm{kg})$, vitamin E $(667 \mathrm{mg} / \mathrm{kg})$, ethoxyquin $(12 \mathrm{mg} / \mathrm{kg})$, and propyl gallate $(2 \mathrm{mg} / \mathrm{kg})$.

sult in representative samples of the mammary gland transcriptome in cows and ewes (Cánovas et al., 2014; Suárez-Vega et al., 2015). A recent study in sheep fed fish oil has also validated this methodology for nutrigenomic analyses in this species (Toral et al., 2016b). Milk samples were collected before the start of the

Table 2. Intake and milk yield and composition in dairy ewes fed a diet without (control) or with $2 \%$ fish oil and displaying mild (RESPON-) or strong (RESPON+) milk fat depression

\begin{tabular}{|c|c|c|c|c|c|c|}
\hline \multirow[b]{2}{*}{ Item } & \multicolumn{3}{|c|}{ Treatment } & \multirow[b]{2}{*}{$\mathrm{SED}^{1}$} & \multicolumn{2}{|l|}{ Contrast $^{2}$} \\
\hline & Control & RESPON- & RESPON+ & & $\begin{array}{c}\text { Control vs. } \\
\text { (RESPON- and RESPON+) }\end{array}$ & $\begin{array}{l}\text { RESPON-vs. } \\
\text { RESPON+ }\end{array}$ \\
\hline Milk, g/d & 2,587 & 2,697 & 2,696 & 151.5 & 0.420 & 0.993 \\
\hline Fat, $\%$ & 5.87 & 5.42 & 4.38 & 0.153 & $<0.001$ & $<0.001$ \\
\hline $\mathrm{g} / \mathrm{d}$ & 152.4 & 143.3 & 117.9 & 9.15 & 0.014 & 0.018 \\
\hline Lactose, \% & 4.96 & 5.10 & 4.96 & 0.068 & 0.296 & 0.059 \\
\hline $\mathrm{g} / \mathrm{d}$ & 128.1 & 137.8 & 133.4 & 8.54 & 0.331 & 0.613 \\
\hline TS, $\%$ & 16.94 & 16.53 & 15.36 & 0.134 & $<0.001$ & $<0.001$ \\
\hline $\mathrm{g} / \mathrm{d}$ & 437.2 & 441.0 & 412.7 & 23.99 & 0.621 & 0.262 \\
\hline
\end{tabular}

${ }^{1} \mathrm{SED}=$ standard error of the difference.

${ }^{2}$ Probability of the orthogonal contrast. 
experiment ( $\mathrm{d}-2$ and -1 ) and after 34 and $35 \mathrm{~d}$ of treatment. Following the protocol by Suárez-Vega et al. (2015), the collection was performed approximately $1 \mathrm{~h}$ after milking and $10 \mathrm{~min}$ after the injection of oxytocin (5 IU/ewe; Facilpart, Laboratorios SYVA, León, Spain) to maximize the concentration of mammary epithelial cells. Udders were cleaned with water and soap and then disinfected with povidone iodine; nipples were also washed with RNaseZap (Ambion, Austin, TX). Individual samples were obtained by hand-milking each half of the mammary gland into an RNase-free $50-\mathrm{mL}$ tube (2 samples/ewe) that was covered with a sterile gauze to filter the milk. Samples were kept in ice and immediately transferred to the laboratory for RNA extraction.

\section{Laboratory Analysis}

Diets and Orts. Dry matter concentration in diets and orts was determined according to the ISO 6496:1999 standard. Diets were also analyzed for ash (ISO 5984:2002), CP (ISO 5983-2:2009), and total starch (K-TSTA kit, Megazyme Intl. Ireland, Wicklow, Ireland). The NDF and ADF were determined using an Ankom ${ }^{2000}$ fiber analyzer (Ankom Technology methods 13 and 12, respectively; Ankom Technology Corp., Macedon, NY); the former was assayed with sodium sulfite and $\alpha$-amylase, and both were expressed with residual ash. Fatty acid methyl esters of lipid in freeze-dried diets were prepared in a 1-step extractiontransesterification procedure using chloroform (Sukhija and Palmquist, 1988) and $2 \%$ (vol/vol) sulfuric acid in methanol (Shingfield et al., 2003), and tridecanoic acid (Sigma-Aldrich, Madrid, Spain) as an internal standard. Methyl esters were separated and quantified using a gas chromatograph (Agilent 7890A GC System, Santa Clara, CA) equipped with a flame-ionization detector and a $100-\mathrm{m}$ fused silica capillary column $(0.25 \mathrm{~mm}$ i.d., 0.2- $\mu \mathrm{m}$ film thickness; CP-SIL 88, CP7489, Varian Ibérica S.A., Madrid, Spain) and hydrogen as the carrier gas (207 kPa, $2.1 \mathrm{~mL} / \mathrm{min})$. Total FAME profile in a $2-\mu \mathrm{L}$ sample volume at a split ratio of 1:50 was determined using the temperature gradient program described in Shingfield et al. (2003). Peak identification was based on retention time comparisons with commercially available standard FAME mixtures (GLC463, Nu-Chek Prep, Elysian, MN; and 18919-1AMP, Supelco, Sigma-Aldrich).

Milk. Milk fat, CP, and TS concentrations were determined by infrared spectrophotometry (ISO 9622:1999) using a MilkoScan FT6000 (Foss, Hillerød, Denmark). Lipid in $1 \mathrm{~mL}$ of milk was extracted using diethylether and hexane $(5: 4, \mathrm{vol} / \mathrm{vol})$ and converted to FAME by base catalyzed transesterification (Shingfield et al., 2003). The total FAME profile was determined by GC using the same chromatograph and temperature gradient program applied for the analysis of feeds, but isomers of 18:1 were further resolved in a separate analysis under isothermal conditions at $170^{\circ} \mathrm{C}$ (Shingfield et al., 2003). Peak identification was based on retention time comparisons with the same FAME mixtures used for the analysis of feeds, other commercially available standards (U-37-M, U-43-M, U-45-M, and U-64-M, NuChek Prep; L6031, L8404, and O5632, Sigma-Aldrich; and 11-1600-8, 20-2024-1, 20-2210-9, 20-2305-1-4, 21-1211-7, 21-1413-7, 21-1614-7, 21-1615-7 and BR mixtures 2 and 3, Larodan, Solna, Sweden), and comparison with reference samples, for which the FA composition was determined based on GC analysis of FAME and GC-MS analysis of corresponding 4,4-dimethyloxazoline derivatives (Bichi et al., 2013).

RNA Isolation and Quantitative PCR. Total RNA in $50 \mathrm{~mL}$ of fresh milk was extracted as reported by Suárez-Vega et al. (2015). Briefly, milk somatic cells were pelleted by centrifugation at $650 \times g$ for $10 \mathrm{~min}$ at $4^{\circ} \mathrm{C}$ in the presence of a final concentration of $0.5 \mathrm{mM}$ EDTA. The cell pellet was washed with $10 \mathrm{~mL}$ of PBS (pH 7.2 and $0.5 \mathrm{~m} M$ EDTA) followed by another centrifugation at $650 \times g$ for $10 \mathrm{~min}$ at $4^{\circ} \mathrm{C}$. Washing and centrifugation procedures were repeated twice using 2 and $1.5 \mathrm{~mL}$ of the same PBS solution. Then, total RNA was extracted and purified from the milk cell pellet with TRIzol (Invitrogen, Carlsbad, CA).

The RNA concentration was determined by fluorometry (Qubit 3.0, Life Technologies, Carlsbad, CA), and the RNA integrity number by capillary electrophoresis (Agilent 2100 Bioanalyzer, Agilent Technologies Inc.). The average RNA integrity number of the samples was $8.0 \pm 0.10$. For quantitative PCR (qPCR) analysis, cDNA was synthesized using a High-Capacity RNAto-cDNA Kit (Applied Biosystems, Foster City, CA). The $\mathrm{qPCR}$ was carried out as described in Bonnet et al. (2013) using a 7500 Real-Time PCR System (Applied Biosystems) and specific primers for the main candidate lipogenic genes involved in milk fat synthesis and the transcription factors that may regulate their expression (Bernard et al., 2008; Bauman et al., 2011; Bionaz et al., 2015). These genes are described in Table 3 and were selected based on previous studies on lipid metabolism in sheep (e.g., Hussein et al., 2013; Carreño et al., 2016; Suárez-Vega et al., 2017). To account for variations in RNA integrity and quantification and cDNA synthesis, mRNA abundance was normalized using the geometric mean of 3 reference genes: eukaryotic translation initiation factor 3 subunit K (EIF3K), peptidylprolyl isomerase A (PPIA), and ubiquitously expressed prefoldin-like chaperone $(U X T)$, all of which have been identified as suitable internal controls (Bon- 
Table 3. Candidate genes analyzed in milk somatic cells (data on primer sequences and quantitative PCR performance are reported in Supplemental Table S1; https://doi.org/10.3168/jds.2017-13354)

\begin{tabular}{lll}
\hline Metabolic pathway & Gene symbol & Gene name \\
\hline Fatty acid activation & ACSS1 & Acyl-CoA synthetase short-chain family member 1 \\
& ACSS2 & Acyl-CoA synthetase short-chain family member 2 \\
De novo fatty acid synthesis & ACACA & Acetyl-CoA carboxylase alpha \\
& FASN & Fatty acid synthase \\
Uptake and intracellular transport of fatty acids & FABP3 & Fatty acid binding protein 3 \\
& LPL & Lipoprotein lipase \\
Desaturation of fatty acids & FADS2 & Fatty acid desaturase 2 \\
& SCD & Stearoyl-CoA desaturase \\
Esterification of fatty acids to glycerol & GPAT4 & Glycerol-3-phosphate acyltransferase 4 \\
& LPIN1 & Lipin 1 \\
Regulation of transcription & APP & Imyloid beta precursor protein \\
& INSIG1 & Kruppel like factor 6 6 \\
& KLF6 & SREBF chaperone \\
& SCAP & Sterol regulatory element binding transcription factor 1 \\
Reference genes & SREBF1 & Eukaryotic translation initiation factor 3 subunit K \\
& EIF3K & Peptidylprolyl isomerase A \\
& PPIA & Ubiquitiously expressed prefoldin like chaperone \\
\hline
\end{tabular}

net et al., 2013). Gene stability was examined using the geNorm procedure (Vandesompele et al., 2002), and the lack of DNA contamination was verified by PCR amplification with primers flanking an intron (e.g., EIF3K and INSIG1). The primer sequences and qPCR performance are shown in Supplemental Tables S1 and S2, respectively (https://doi.org/10.3168/jds .2017-13354). The abundance of gene transcripts was calculated using a 5-point calibration curve generated from the serial dilution of a cDNA pool, prepared by mixing equal volumes of all samples, and expressed as the $\log _{2}$ value of the mRNA copy number relative to the geometric mean of the 3 reference genes.

\section{Calculations and Statistical Analysis}

All statistical analyses were performed using the SAS software package (version 9.4, SAS Institute Inc., Cary, NC). Data were analyzed by one-way analysis of covariance with a model that included the fixed effect of treatments (control, RESPON-, and RESPON+; mean values over $\mathrm{d} 31,32$, and 33 for animal performance and milk FA composition, and d 34 or 35 for transcript mRNA abundances), and measurements at the end of the adaptation period (mean values over $\mathrm{d}-5,-4$, and -3 for animal performance and milk FA composition, and $\mathrm{d}-2$ or -1 for transcript mRNA abundances) as a covariate. Animals were nested within treatment. Previously defined orthogonal contrasts were used to confirm the effects of fish oil supplementation [i.e., control vs. MFD (RESPON+ and RESPON-)], as well as to examine differences in the response within ewes with diet-induced MFD (i.e., RESPON+ vs. RESPON-). Differences were declared significant at $P<0.05$ and considered a trend toward significance at $P<0.10$. Least squares means are reported.

\section{RESULTS}

\section{Animal Performance}

As shown in Table 2, DMI tended to be slightly lower in ewes fed the fish-oil-supplemented diet, but there were no significant differences between RESPON - and RESPON+ $(P=0.710)$. This slight drop was not reflected in milk production, which was similar among the 3 groups $(P=0.420)$. In contrast, based on the experimental design, the addition of fish oil decreased the concentration of milk fat $(P<0.001)$. This reduction was much stronger in RESPON+ $(-25.4 \%$ compared with the control) than in RESPON- $-7.7 \% ; P$ $<0.001$ ), and the same pattern was observed for daily milk fat production ( -22.6 and $-6.0 \%$, respectively; $P<0.05)$. Protein concentrations were similarly reduced in RESPON - and RESPON+ $(P<0.05)$, and those of lactose tended to differ between the 2 latter $(P=0.059)$ : the proportion was marginally greater in RESPON - but both values were comparable to the control $(P=0.296)$. Although yields of protein, lactose, and TS were not statistically affected $(P>0.10)$, the proportion of TS mirrored the decrease observed in milk fat and protein contents $(P<0.001)$.

\section{Milk FA Profile}

As presented in Table 4 and Supplemental Table S3 (https://doi.org/10.3168/jds.2017-13354), feeding fish oil decreased the milk concentration of several indi- 
vidual short- and medium-chain FA (e.g., 14:0; $P<$ 0.05), including some odd- or branched-chain FA (e.g., iso 15:0, anteiso 15:0, iso 16:0, or anteiso 17:0; $P<$ $0.05)$. At the same time, some others were significantly increased (e.g., cis-9 10:1, most 16:1 isomers, iso 17:0 or 17:0; $P<0.05)$. In this group of FA, only cis-9 10:1 ( $P$ $=0.091)$, trans 15:1, and cis-7 16:1 $(P<0.05)$ differed between RESPON - and RESPON+, with greater proportions being found in the latter treatment.

Diet supplementation with fish oil had a strong effect on 18:0, with milk concentration in RESPON- and RESPON + averaging just $23 \%$ of the control value $(P<$ 0.001), but without significant changes linked to MFD severity. These were not found in 10-oxo-18:0 either, despite the significant increase due to diet supplementation $(P<0.01)$. The decrease in stearic acid was reflected in cis-9 18:1 (-45\% compared with the control; $P<0.001)$. In contrast, most other cis and trans 18:1 isomer contents were higher in milk from supplemented ewes $(P<0.01)$. Within this group, the sum of trans 18:1 tended to be more abundant in RESPON+ than in RESPON $-(P=0.082)$, and trans- $6+7+818: 1$ was greater in the latter group $(P<0.05)$.

The concentration of CLA was significantly enhanced by dietary marine lipids $(P<0.001)$, with trans-10, cis-12 CLA showing a higher value in RESPON- compared with RESPON $+(P<0.01)$. The sum of nonconjugated 18:2 was unaffected by the treatment $(P=0.973)$ due to the counteracting effects of decreases in cis-9 cis-12 18:2 and increases in most other isomers. No significant differences between RESPON- and RESPON+ were detected in these FA.

Diet supplementation with fish oil led to a milk fat profile with a greater concentration of very long chain FA (e.g., unsaturated C20 and C22, 20:5n-3; 22:5n-3 or $22: 6 \mathrm{n}-3 ; P<0.001)$. Within this group, milk concentrations of $20: 2 \mathrm{n}-6$ and $20: 4 \mathrm{n}-3$ were favored more in RESPON - than in RESPON+ $(P<0.01)$. This pattern was also followed by cis-13 $22: 1+20: 3 n-3$ ( $P$ $=0.070)$, whereas $22: 5 \mathrm{n}-6$ and $22: 6 \mathrm{n}-3$ tended to be higher in RESPON+ $(P<0.10)$.

Except for trans-10,cis-12 CLA and 22:6n-3, mentioned above, none of the other putative antilipogenic FA (e.g., cis-9 16:1, 10-oxo-18:0, trans-10 18:1, cis-11 18:1, trans-9,cis-11 CLA, or trans-10,cis-15 18:2, which coeluted with trans-11,cis-15 18:2) differed significantly in relation to MFD intensity (i.e., between RESPONand RESPON+).

However, clear differences were detected between the 2 groups of supplemented ewes in the contribution of major milk FA classes to MFD, with molar yields of FA derived from de novo synthesis $(<\mathrm{C} 16)$, plasma uptake $(>\mathrm{C} 16)$, or both sources (C16) always being lower in RESPON+ than in RESPON- $(P<0.10)$. Compared with the control, major FA groups decreased to a similar extent in ewes showing a marked response to fish oil (on average, $-23 \%$ ), whereas the reduction in molar yields of $<\mathrm{C} 16$ and $\mathrm{C} 16 \mathrm{FA}$ was less severe in those with a mild MFD ( -14 and $-8 \%$, respectively), and no variation was observed in that of $>\mathrm{C} 16 \mathrm{FA}$.

\section{mRNA Abundance of Candidate Genes}

The transcript abundance of the 3 reference genes (EIF3K, PPIA, and UXT) was not significantly affected by lipid supplementation or susceptibility to MFD, and their stability was the greatest among the set of quantified genes.

The mRNA relative abundances of candidate lipogenic genes and related transcription factors in milk somatic cells are reported in Table 5. Compared with the control, ACSS2, FASN, LPIN1, and FADS2 tended to be downregulated in ewes fed fish oil $(P<0.10)$. Numerical decreases were also observed in $A C A C A$ and ACSS1 but these changes did not reach the required level of significance ( $P=0.119$ and 0.127 , respectively).

Despite the lack of significance of the contrast comparing control versus MFD, SCD and GPAT 4 tended to differ between RESPON - and RESPON+ $(P=0.090$ and 0.062 , respectively). The mRNA abundance of the former was decreased in RESPON+, whereas that of the latter, GPAT4, was very similar in this group and in the control and higher in animals showing only a slight susceptibility to MFD (i.e., RESPON-).

Concerning the analyzed transcription factors, only the expression of INSIG1 tended to be reduced by the marine lipid $(P=0.071)$. No differences were observed between RESPON - and RESPON+ for mRNA abundances of other transcriptional regulators, which in some cases showed high variation within groups (e.g., $A P P$ and $K L F 6$ ).

\section{DISCUSSION}

Dairy ewes are less prone than cows to MFD but suffer from this syndrome when marine lipids rich in n-3 PUFA are added to their diet to improve milk FA composition (Capper et al., 2007; Bichi et al., 2013; Carreño et al., 2016). However, large individual differences in MFD severity are present, and the reasons behind this variability remain uncertain.

Experimental conditions (e.g., fish oil dose, and TMR composition and forage:concentrate ratio) were selected to mimic the wide range of individual variation in the extent of MFD that we had consistently observed in lactating sheep (e.g., Bichi et al., 2013; Toral et al., 2015, 2016a; Carreño et al., 2016). As expected, diet supplementation with marine oil elicited MFD, but 
responses in terms of decreased milk fat concentration and yield differed largely between individual ewes. On the contrary, other animal performance parameters were similarly affected by the marine lipid in all ewes, regardless of their responsiveness to MFD.

Lowered feed intake with dietary fish oil (Invernizzi et al., 2010; Kairenius et al., 2015; Toral et al., 2016a) was probably explained by the greater energy density of the ration, thus preventing a reduction in milk yield. Consequences of feeding marine lipids to sheep include decreases, no effects or even increases in total milk yield (Reynolds et al., 2006; Tsiplakou and Zervas, 2013; Toral et al., 2016b), but similar results in RESPON+ and RESPON - would rule out a causal relationship between changes in this parameter and extent of MFD in ovine. Reductions in milk protein concentration (Pirondini et al., 2015; Carreño et al., 2016; Toral et al., 2016a) were also comparable in the 2 groups of ewes fed fish oil. Curiously, milk lactose concentration tended to differ between RESPON- and RESPON+. However, its marginal variation and the apparent lack of association with marine lipid-induced MFD in earlier studies in sheep and cows (Angulo et al., 2012; Bichi et al., 2013; Pirondini et al., 2015) suggest that this result might have no biological relevance.

Despite individual differences in ewe responses to the diet inducing MFD, milk content of FA with potentially beneficial or detrimental effects on human health (Lock and Bauman, 2004; Salter, 2013) was very similar in all supplemented animals. Thus, milk from both RESPON+ and RESPON - showed rather uniform increases in the concentration of cis-9,trans-11 CLA, trans-11 18:1, or total PUFA, and decreases in medium-chain SFA 12:0 and 14:0, which may have positive health implications (Lock and Bauman, 2004; Salter, 2013). The very few exceptions to this general trend include minor MUFA, such as cis-7 16:1, to which anti-inflammatory effects have recently been attributed (Guijas et al., 2016), and very long-chain PUFA, such as 22:6n-3, with well-documented health-promoting activity (Salter, 2013). The greater the susceptibility of ewes to diet-induced MFD, the greater the concentration of these 2 FA (i.e., cis-7 16:1 and 22:6n-3) in their milk.

Contrary to our first hypothesis, milk concentrations of FA with confirmed or putative inhibitory activity against lipogenesis appeared quite alike in RESPON+ and RESPON-. This was especially surprising for trans-10,cis-12 CLA because its greatest content was found in RESPON-. Notwithstanding the limitations of GC for the quantification of some CLA isomers, this result would be in line with a marginal role of trans10,cis-12 CLA in marine lipid-induced MFD (Bichi et al., 2013; Kairenius et al., 2015; Toral et al., 2015).
The lack of association between concentrations of this antilipogenic FA in milk and decreases in fat content in ruminants fed fish oil or microalgae contrasts with observations during CLA-induced MFD, which highlights differences between both conditions (Shingfield et al., 2010; Angulo et al., 2012; Toral et al., 2017). Other ruminal $\mathrm{BH}$ intermediates that have been related to the low-fat milk syndrome, such as trans-9,cis-11 CLA, which has shown evidence of inhibitory effects in dairy cows (Shingfield et al., 2010), displayed similar increases in the 2 groups of supplemented ewes. This also occurred for trans-10 18:1, for which involvement in MFD is currently ambiguous (Kadegowda et al., 2009; Bauman et al., 2011), and the less-known candidate milk fat inhibitors trans-10,cis-15 18:2 and 10-oxo-18:0 (Alves and Bessa, 2014; Kairenius et al., 2015; Toral et al., 2015, 2017).

Tentative antilipogenic activity has also been attributed to some MUFA that are present in marine lipids, namely cis-9 16:1 and cis-11 18:1 (Burns et al., 2012). The putative action of these compounds, in combination with potential suppressive effects of very long chain n-3 PUFA on lipogenic gene expression (Kadegowda et al., 2009), might explain the reductions in milk fat concentration observed after postruminal infusions of fish oil (Loor et al., 2005; Dallaire et al., 2014). Although the concentration of $22: 6 \mathrm{n}-3$ was greater in RESPON+, results by Loor et al. (2005) would prevent the sole attribution of differences in responsiveness to this FA.

Significant variations were also not detected between RESPON + and RESPON - in the milk concentrations of 18:0 and cis-9 18:1, which agrees with a previous study in dairy ewes (Toral et al., 2016a) that challenged the association of MFD with a shortage of 18:0 for mammary cis-9 18:1 synthesis and its possible effect on the maintenance of milk fat fluidity (Loor et al., 2005; Shingfield et al., 2010).

Overall, our milk FA profile results would oblige us to reject the hypothesis that milk concentration of identified FA with potential antilipogenic effects is responsible for individual differences in MFD extent in ewes fed fish oil. Nevertheless, it could be speculated that some other, as yet unidentified, FA might be more relevant or that sensitivity to the candidate milk fat inhibitors mentioned above may vary between individuals. Regarding the first supposition and despite the comprehensive FA profile provided in this report, it is difficult to suggest new candidates among the few FA showing significant differences between RESPON+ and RESPON-. We are not aware of any study on the effect of cis-9 10:1 and trans 15:1 on mammary metabolism, and although trans-7 18:1 decreased lipogenic gene expression in lactating mice (Kadegowda et al., 2010), the peak containing this 18:1 isomer was more 
Table 4. Milk fatty acid (FA) composition and molar yield in dairy ewes fed a diet without (control) or with $2 \%$ fish oil and displaying mild (RESPON-) or strong (RESPON+) milk fat depression (data on additional FA are reported in Supplemental Table S3; https://doi. org/10.3168/jds.2017-13354)

Treatment

Item

FA, g/100 g of total FA

4:0

$6: 0$

$8: 0$

10:0

cis-9 10:1

12:0

cis-9 12:1

14:0

cis-9 14:1

15:0

15:0 anteiso

15:0 iso

trans-5 15:1

trans $-6+7$ 15:1

16:0

16:0 iso

cis-7 16:1

cis-9 16:1

trans-6+7 16:1

trans-8 16:1

trans-9 16:1

17:0

17:0 anteiso

17:0 iso

18:0

10-oxo-18:0

cis-9 18:1

cis-11 18:1

cis-12 18:1

cis-13 18:1

$\Sigma$ cis 18:1

trans $-6+7+8$ 18:1

trans-9 18:1

trans-10 18:1

trans-11 18:1

trans-12 18:1

trans-13+14 18:1

trans-15 18:1

$\Sigma$ trans 18:1

cis-9, cis-12 18:2

cis-9,trans-12 18:2

trans-9,cis-12 18:2

trans-11, cis-15 + trans-10,cis-15 18:2

trans-9,trans-12 18:2

$\Sigma$ nonconjugated 18:2

cis-9,trans-11 $\mathrm{CLA}^{3}$

trans-9,cis-11 CLA

trans-10,cis-12 CLA

$\Sigma \mathrm{CLA}$

$18: 3 n-3^{4}$

20:0

trans-11 20:1

¿ 20:1

$20: 2 \mathrm{n}-6$

20:4n-6

$20: 3 \mathrm{n}-3+$ cis-13 22:1

20:4n-3

$20: 5 n-3$

$\Sigma$ unsaturated C20
Contrast $^{2}$

Control vs.

(RESPON- and RESPON-vs. RESPON+) RESPON+

\begin{tabular}{|c|c|c|c|c|c|}
\hline 3.35 & 3.01 & 3.09 & 0.189 & 0.096 & 0.632 \\
\hline 2.95 & 2.98 & 3.08 & 0.130 & 0.496 & 0.399 \\
\hline 3.02 & 3.16 & 3.33 & 0.179 & 0.168 & 0.383 \\
\hline 10.37 & 9.49 & 10.29 & 0.501 & 0.279 & 0.136 \\
\hline 0.27 & 0.29 & 0.33 & 0.017 & 0.028 & 0.091 \\
\hline 6.16 & 5.02 & 5.67 & 0.486 & 0.066 & 0.180 \\
\hline 0.11 & 0.08 & 0.09 & 0.016 & 0.121 & 0.407 \\
\hline 12.44 & 10.94 & 11.54 & 0.482 & 0.011 & 0.201 \\
\hline 0.16 & 0.16 & 0.17 & 0.022 & 0.809 & 0.909 \\
\hline 1.00 & 0.93 & 0.93 & 0.058 & 0.158 & 0.927 \\
\hline 0.48 & 0.34 & 0.36 & 0.038 & 0.002 & 0.749 \\
\hline 0.27 & 0.22 & 0.23 & 0.021 & 0.027 & 0.539 \\
\hline 0.15 & 0.12 & 0.17 & 0.017 & 0.859 & 0.009 \\
\hline 0.02 & 0.03 & 0.03 & 0.003 & $<0.001$ & 0.010 \\
\hline 27.15 & 26.12 & 25.96 & 0.861 & 0.159 & 0.857 \\
\hline 0.29 & 0.22 & 0.20 & 0.031 & 0.012 & 0.518 \\
\hline 0.25 & 0.25 & 0.29 & 0.018 & 0.220 & 0.018 \\
\hline 0.67 & 1.07 & 1.12 & 0.079 & $<0.001$ & 0.532 \\
\hline 0.05 & 0.14 & 0.16 & 0.010 & $<0.001$ & 0.203 \\
\hline 0.01 & 0.05 & 0.06 & 0.011 & $<0.001$ & 0.524 \\
\hline 0.05 & 0.41 & 0.43 & 0.058 & $<0.001$ & 0.747 \\
\hline 0.58 & 0.69 & 0.63 & 0.041 & 0.019 & 0.196 \\
\hline 0.43 & 0.29 & 0.33 & 0.030 & $<0.001$ & 0.257 \\
\hline 0.37 & 0.44 & 0.46 & 0.025 & 0.003 & 0.569 \\
\hline 7.29 & 2.15 & 1.26 & 0.517 & $<0.001$ & 0.114 \\
\hline 0.02 & 0.37 & 0.37 & 0.035 & $<0.001$ & 0.994 \\
\hline 12.11 & 7.52 & 5.86 & 0.936 & $<0.001$ & 0.103 \\
\hline 0.36 & 0.75 & 0.79 & 0.038 & $<0.001$ & 0.241 \\
\hline 0.20 & 0.10 & 0.08 & 0.016 & $<0.001$ & 0.156 \\
\hline 0.03 & 0.06 & 0.06 & 0.004 & $<0.001$ & 0.800 \\
\hline 12.83 & 8.52 & 6.89 & 0.960 & $<0.001$ & 0.117 \\
\hline 0.17 & 0.30 & 0.23 & 0.032 & 0.006 & 0.039 \\
\hline 0.14 & 0.50 & 0.49 & 0.049 & $<0.001$ & 0.761 \\
\hline 0.05 & 1.00 & 1.47 & 0.294 & $<0.001$ & 0.136 \\
\hline 0.59 & 5.06 & 5.45 & 0.755 & $<0.001$ & 0.597 \\
\hline 0.21 & 0.61 & 0.57 & 0.057 & $<0.001$ & 0.496 \\
\hline 0.13 & 0.35 & 0.40 & 0.064 & $<0.001$ & 0.401 \\
\hline 0.17 & 0.18 & 0.18 & 0.018 & 0.526 & 0.977 \\
\hline 1.79 & 7.87 & 8.70 & 0.437 & $<0.001$ & 0.082 \\
\hline 2.29 & 1.56 & 1.64 & 0.109 & $<0.001$ & 0.503 \\
\hline 0.03 & 0.08 & 0.07 & 0.008 & $<0.001$ & 0.263 \\
\hline 0.03 & 0.09 & 0.09 & 0.008 & $<0.001$ & 0.704 \\
\hline 0.06 & 0.37 & 0.46 & 0.050 & $<0.001$ & 0.110 \\
\hline 0.01 & 0.04 & 0.05 & 0.013 & 0.014 & 0.298 \\
\hline 2.89 & 2.83 & 2.94 & 0.139 & 0.973 & 0.440 \\
\hline 0.34 & 2.57 & 2.45 & 0.254 & $<0.001$ & 0.629 \\
\hline 0.01 & 0.04 & 0.05 & 0.009 & $<0.001$ & 0.746 \\
\hline$<0.001$ & 0.02 & 0.01 & 0.002 & $<0.001$ & 0.006 \\
\hline 0.37 & 2.68 & 2.54 & 0.251 & $<0.001$ & 0.600 \\
\hline 0.70 & 0.78 & 0.82 & 0.029 & 0.002 & 0.155 \\
\hline 0.20 & 0.23 & 0.22 & 0.012 & 0.013 & 0.527 \\
\hline 0.01 & 0.03 & 0.02 & 0.003 & $<0.001$ & 0.506 \\
\hline 0.06 & 0.24 & 0.21 & 0.023 & $<0.001$ & 0.231 \\
\hline 0.03 & 0.10 & 0.09 & 0.006 & $<0.001$ & 0.009 \\
\hline 0.16 & 0.18 & 0.21 & 0.020 & 0.033 & 0.141 \\
\hline 0.02 & 0.10 & 0.08 & 0.010 & $<0.001$ & 0.070 \\
\hline 0.01 & 0.16 & 0.13 & 0.007 & $<0.001$ & $<0.001$ \\
\hline 0.05 & 0.40 & 0.44 & 0.049 & $<0.001$ & 0.440 \\
\hline 0.44 & 1.46 & 1.40 & 0.053 & $<0.001$ & 0.230 \\
\hline
\end{tabular}

Continued 
Table 4 (Continued). Milk fatty acid (FA) composition and molar yield in dairy ewes fed a diet without (control) or with $2 \%$ fish oil and displaying mild (RESPON-) or strong (RESPON+) milk fat depression (data on additional FA are reported in Supplemental Table S3; https:// doi.org/10.3168/jds.2017-13354)

\begin{tabular}{|c|c|c|c|c|c|c|}
\hline Item & \multicolumn{3}{|c|}{ Treatment } & $\mathrm{SED}^{1}$ & \multicolumn{2}{|c|}{ Contrast $^{2}$} \\
\hline $22: 0$ & 0.11 & 0.12 & 0.12 & 0.010 & 0.064 & 0.950 \\
\hline trans-13 22:1 & $<0.001$ & 0.02 & 0.03 & 0.004 & $<0.001$ & 0.130 \\
\hline$\Sigma 22: 1$ & 0.02 & 0.20 & 0.23 & 0.021 & $<0.001$ & 0.196 \\
\hline$\Sigma$ unsaturated $\mathrm{C} 22$ & 0.21 & 2.87 & 3.09 & 0.238 & $<0.001$ & 0.351 \\
\hline \multicolumn{7}{|l|}{ Molar yield, mmol/d } \\
\hline$<\mathrm{C} 16 \mathrm{FA}$ & 344.0 & 295.3 & 260.8 & 16.85 & $<0.001$ & 0.065 \\
\hline C16 FA & 162.7 & 149.0 & 123.3 & 10.38 & 0.012 & 0.028 \\
\hline$>\mathrm{C} 16 \mathrm{FA}$ & 145.5 & 147.5 & 113.5 & 13.62 & 0.185 & 0.030 \\
\hline
\end{tabular}

${ }^{1} \mathrm{SED}=$ standard error of the difference.

${ }^{2}$ Probability of the orthogonal contrast.

${ }^{3}$ Contains trans-7,cis-9 and trans-8,cis-10 CLA as minor components.

${ }^{4}$ Coelutes with cis-11 20:1.

abundant in RESPON - than in RESPON+. The same occurred with 20:2n-6, 20:4n-3, or the sum of cis-13 22:1 $+20: 3 \mathrm{n}-3$. Support for the second speculation, related to individual differences in sensitivity to antilipogenic FA, would require further research, but unlike responses to specific milk fat inhibitors, has been observed under almost identical conditions. For instance, when Assaf ewes from the same experimental flock were fed a diet supplemented with a similar amount of trans-10,cis-12 CLA, the reduction in milk fat concentration averaged
$-18 \%$ in a first trial (Toral et al., 2015) and $-33 \%$ in a second one (Toral et al., 2017).

The similarity in individual milk FA proportions in all ewes fed fish oil contrasts with associated differences in major milk FA groups. Based on earlier studies in dairy sheep fed marine lipids, we calculated that the average contribution of $<\mathrm{C} 16, \mathrm{C} 16$, and $>\mathrm{C} 16 \mathrm{FA}$, on a molar basis, to MFD represent $\approx 51,22$, and $27 \%$, respectively, of the decrease in total milk FA yield (Bichi et al., 2013; Toral et al., 2015, 2016a, 2017; Carreño et al., 2016).

Table 5. mRNA relative abundance ( $\log _{2}$ transformed data; arbitrary units) of lipogenic genes in milk somatic cells from dairy ewes fed a diet without (control) or with $2 \%$ fish oil and displaying mild (RESPON-) or strong (RESPON+) milk fat depression

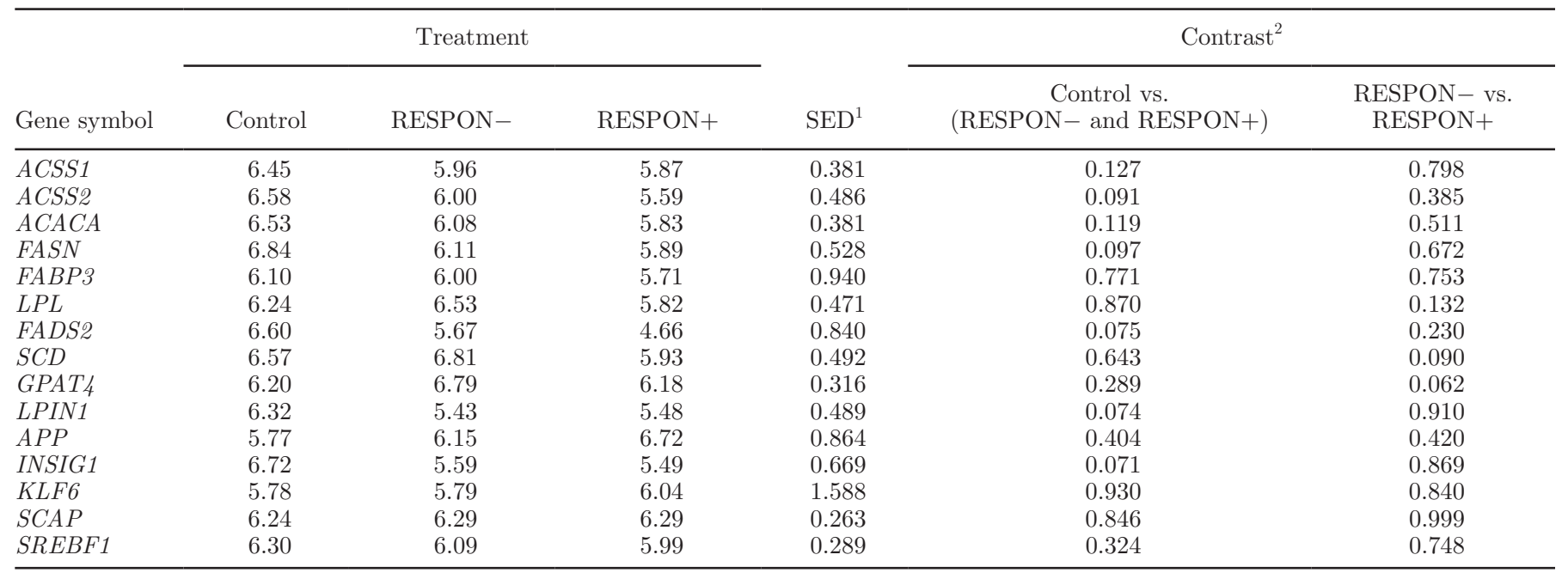

${ }^{1} \mathrm{SED}=$ standard error of the difference.

${ }^{2}$ Probability of the orthogonal contrast. 
These values are similar to those found in RESPON+ (i.e., 54, 25, and 21\%, respectively) but far from the results in RESPON-, where $<\mathrm{C} 16 \mathrm{FA}$ accounted for $81 \%$ of the reductions in total milk FA secretion and $>$ C16 FA made no contribution. Therefore, some of the major mechanisms involved in de novo FA synthesis and uptake of preformed FA from plasma were not equally inhibited in animals displaying different degrees of MFD. It may be speculated that mechanisms linked to the uptake of $>\mathrm{C} 16 \mathrm{FA}$ were better preserved in RESPON-, which would prevent severe MFD.

These results, however, could not be related to changes in candidate gene expression in milk somatic cells in this study. Feeding fish oil decreased the mRNA abundance of key genes responsible for FA activation and de novo synthesis (i.e., ACSS2 and FASN, respectively), which is consistent with previous studies in ewes and cows (e.g., Ahnadi et al., 2002; Carreño et al., 2016; Suárez-Vega et al., 2017), but this downregulation was similar in RESPON+ and RESPON-. The transcript abundance of other genes involved in these metabolic pathways (e.g., ACSS1 and ACACA; Bernard et al., 2008; Bionaz and Loor, 2008) was not significantly affected, which contrasts with expectations based on results recorded in sheep and cows (Mach et al., 2011; Ticiani et al., 2016; Toral et al., 2016b) and numerical differences relative to the control. This could be due to high variation in gene expression within groups and limited number of individuals, which might also account for the lack of significance of the contrast RESPON+ versus RESPON- for $L P L$. Although this gene plays a major role in plasma FA uptake, its expression is not specific to mammary epithelial cells and has a complex posttranscriptional regulation (Camps et al., 1990; Bernard et al., 2008), which may explain its often stable transcript abundances under MFD (Ahnadi et al., 2002; Invernizzi et al., 2010; Toral et al., 2017). Differences in the contribution of major FA groups to MFD were also not related to the mRNA abundance of $F A B P 3$, which participates in mammary long-chain FA uptake and transport in ruminants (Bernard et al., 2008). Nonetheless, the inconsistent behavior of FABP3 (Invernizzi et al., 2010; Hussein et al., 2013; Carreño et al., 2016) makes its involvement in MFD unclear.

The transcription factor SREBF1 regulates the expression of most of the quantified candidate genes (e.g., ACSS2, ACACA, FASN, and FABP3; Ma and Corl, 2012) and its role appears to be crucial in the low-fat milk condition (Harvatine and Bauman, 2006; Bionaz et al., 2015; Suárez-Vega et al., 2017). However, decreases in its mRNA abundance are not always detected in ewes showing MFD (Ticiani et al., 2016; Toral et al., 2017), which concurs with our observations. This might be accounted for, at least in part, by its complex posttranscriptional regulation, which involves the mediation of SCAP and INSIG1 (Bernard et al., 2008; Bionaz et al., 2015). Decreased transcript abundance of the latter is a common finding in diet-induced MFD (Harvatine and Bauman, 2006; Carreño et al., 2016; Toral et al., 2016b), but our results suggest that it is not related to responsiveness to fish oil consumption.

Differences between RESPON - and RESPON+ were only detected for $S C D$ and GPAT4, with a tendency toward lower expression in RESPON+ in both cases. Evidence from in vitro assays indicates a direct and negative effect of very long chain n-3 PUFA on mammary $S C D$ expression (Kadegowda et al., 2009), with RESPON+ having the greatest milk concentration of 22:6n-3. Nevertheless, the mRNA abundance of this $\Delta^{9}$ desaturase showed no relationship with proportions of its products or substrates in the milk from both groups. The interpretation of GPAT4 results is even less clear given its role in triacylglycerol synthesis (Takeuchi and Reue, 2009), a metabolic process that was probably hindered by LPIN1 downregulation (Takeuchi and Reue, 2009; Zhu et al., 2015). Moreover, little and inconsistent information exists about the involvement of GPAT4 in MFD in ewes (Hussein et al., 2013; Carreño et al., 2016; Toral et al., 2017), which might exclude a major role of this gene in MFD severity.

Some novel candidate genes, such as KLF6, APP, or FADS2, were selected after RNA sequencing of the mammary transcriptome in lactating sheep fed fish oil (Suárez-Vega et al., 2017). However, despite the potential involvement of KLF6 and APP in SREBP1 activity and maturation, respectively (Pierrot et al., 2013; Pawlak et al., 2015), their transcript abundance was unaffected in our trial. The trend toward downregulation of FADS2, which codes for $\Delta^{6}$-desaturase, was consistent with findings of Suárez-Vega et al. (2017). Yet, this does not necessarily reflect a causal relationship with MFD, and might be linked to an increased availability of very long chain PUFA (FADS2 products) in supplemented ewes, counteracting the need for this desaturation in mammary epithelial cells.

Overall, although our results do not support the 2 initial hypotheses, data on milk FA profile, particularly on patterns of antilipogenic FA variation, and on expression of genes involved in mammary lipogenesis in ewes displaying different degrees of MFD may advance our knowledge on how marine lipids cause this condition in sheep and eventually help troubleshoot the problem. However, further research must be pursued to elucidate mechanisms underlying individual differences in MFD extent, including functional analysis of mammary transcriptome or ruminal metabolism. 


\section{CONCLUSIONS}

In dairy ewes, diet supplementation with fish oil can induce a strong (RESPON+) or just a mild (RESPON-) decrease in milk fat concentration and yield. This individual variation is not associated with relevant changes in the milk FA profile, including putative milk fat inhibitors (e.g., cis-9 16:1, trans-10 and cis-11 18:1, trans-10,cis-15 18:2, trans-9,cis-11 CLA, and 10-oxo-18:0). These results reject the hypothesis that milk concentration of potentially antilipogenic FA may explain the individual variability in MFD. However, average contributions of $<\mathrm{C} 16, \mathrm{C} 16$, and $>\mathrm{C} 16$ FA to reductions in total milk FA yield vary greatly between animals displaying different degrees of MFD as >C16 makes no contribution in RESPON-. Tendencies toward lower mRNA abundances of $S C D$ and GPAT4 in more responsive animals (RESPON+) offer no support for the second hypothesis, which focused on the relevance of transcriptional regulation of mammary lipogenesis to explain MFD severity.

\section{ACKNOWLEDGMENTS}

This study was supported by the Spanish Ministry of Economy and Competitiveness (MINECO; AGL201454587-R). The authors thank L. Rodríguez (FPI predoctoral grant, MINECO) and A. G. Mendoza for their help with experimental animals and fatty acid analysis. P. G. Toral benefits from a Ramón y Cajal research contract from the MINECO. Co-funding by the European Regional Development Fund is also acknowledged.

\section{REFERENCES}

Ahnadi, C. E., N. Beswick, L. Delbecchi, J. J. Kennelly, and P. Lacasse. 2002. Addition of fish oil to diets for dairy cows. II. Effects on milk fat and gene expression of mammary lipogenic enzymes. J. Dairy Res. 69:521-531.

Alves, S. P., and R. J. B. Bessa. 2014. The trans-10,cis-15 18:2: A missing intermediate of trans-10 shifted rumen biohydrogenation pathway? Lipids 49:527-541.

Angulo, J., L. Mahecha, K. Nuernberg, G. Nuernberg, D. Dannenberger, M. Olivera, M. Boutinaud, C. Leroux, E. Albrecht, and L. Bernard. 2012. Effects of polyunsaturated fatty acids from plant oils and algae on milk fat yield and composition are associated with mammary lipogenic and SREBF1 gene expression. Animal 6:1961-1972.

Bauman, D. E., and J. M. Griinari. 2001. Regulation and nutritional manipulation of milk fat: Low-fat milk syndrome. Livest. Prod. Sci. 70:15-29.

Bauman, D. E., K. J. Harvatine, and A. L. Lock. 2011. Nutrigenomics, rumen-derived bioactive fatty acids, and the regulation of milk fat synthesis. Annu. Rev. Nutr. 31:299-319.

Bernard, L., C. Leroux, and Y. Chilliard. 2008. Expression and nutritional regulation of lipogenic genes in the ruminant lactating mammary gland. Adv. Exp. Med. Biol. 606:67-108.

Bichi, E., G. Hervás, P. G. Toral, J. J. Loor, and P. Frutos. 2013. Milk fat depression induced by dietary marine algae in dairy ewes:
Persistency of milk fatty acid composition and animal performance responses. J. Dairy Sci. 96:524-532.

Bionaz, M., and J. J. Loor. 2008. Gene networks driving bovine milk fat synthesis during the lactation cycle. BMC Genomics 9:366.

Bionaz, M., J. Osorio, and J. J. Loor. 2015. Nutrigenomics in dairy cows: Nutrients, transcription factors, and techniques. J. Anim. Sci. 93:5531-5553.

BOE (Boletín Oficial del Estado). 2013. Royal Decree 53/2013, of 8 February, on the protection of animals used for experimental purposes. Pages 11370-11421 in Boletín Oficial del Estado. Spanish Government Publishing, Madrid, Spain.

Bonnet, M., L. Bernard, S. Bes, and C. Leroux. 2013. Selection of reference genes for quantitative real-time PCR normalisation in adipose tissue, muscle, liver and mammary gland from ruminants. Animal 7:1344-1353.

Burns, T. A., A. K. G. Kadegowda, S. K. Duckett, S. L. Pratt, and T. C. Jenkins. 2012. Palmitoleic (16:1 cis-9) and cis-vaccenic (18:1 cis-11) acid alter lipogenesis in bovine adipocyte cultures. Lipids 47:1143-1153.

Camps, L., M. Reina, M. Llobera, S. Vilaró, and T. Olivecrona. 1990. Lipoprotein lipase: Cellular origin and functional distribution. Am. J. Physiol. 258:C673-C681.

Cánovas, A., G. Rincón, C. Bevilacqua, A. Islas-Trejo, P. Brenaut, R. C. Hovey, M. Boutinaud, C. Morgenthaler, M. K. VanKlompenberg, P. Martin, and J. F. Medrano. 2014. Comparison of five different RNA sources to examine the lactating bovine mammary gland transcriptome using RNA-sequencing. Sci. Rep. 4:5297.

Capper, J. L., R. G. Wilkinson, A. M. Mackenzie, and L. A. Sinclair. 2007. The effect of fish oil supplementation of pregnant and lactating ewes on milk production and lamb performance. Animal 1:889-898.

Carreño, D., G. Hervás, P. G. Toral, T. Castro-Carrera, and P. Frutos. 2016. Fish oil-induced milk fat depression and associated downregulation of mammary lipogenic genes in dairy ewes. J. Dairy Sci. 99:7971-7981.

Dallaire, M. P., H. Taga, L. Ma, B. A. Corl, R. Gervais, Y. Lebeuf, F. J. Richard, and P. Y. Chouinard. 2014. Effects of abomasal infusion of conjugated linoleic acids, Sterculia foetida oil, and fish oil on production performance and the extent of fatty acid $\Delta^{9}-$ desaturation in dairy cows. J. Dairy Sci. 97:6411-6425.

EU (European Union). 2010. Directive 2010/63/EU of the European Parliament and of the Council of 22 September 2010 on the protection of animals used for scientific purposes. Off. J. Eur. Union L 276:33-79.

Guijas, C., C. Meana, A. M. Astudillo, M. A. Balboa, and J. Balsinde. 2016. Foamy monocytes are enriched in cis-7-hexadecenoic fatty acid (16:1n-9), a possible biomarker for early detection of cardiovascular disease. Cell Chem. Biol. 23:689-699.

Haenlein, G. F. W. 2007. About the evolution of goat and sheep milk production. Small Rumin. Res. 68:3-6.

Harvatine, K. J., and D. E. Bauman. 2006. SREBP1 and thyroid hormone responsive spot 14 (S14) are involved in the regulation of bovine mammary lipid synthesis during diet-induced milk fat depression and treatment with CLA. J. Nutr. 136:2468-2474.

Hussein, M., K. H. Harvatine, W. M. P. B. Weerasinghe, L. A. Sinclair, and D. E. Bauman. 2013. Conjugated linoleic acid-induced milk fat depression in lactating ewes is accompanied by reduced expression of mammary genes involved in lipid synthesis. J. Dairy Sci. 96:3825-3834.

Invernizzi, G., B. J. Thering, M. A. McGuire, G. Savoini, and J. J. Loor. 2010. Sustained upregulation of stearoyl-CoA desaturase in bovine mammary tissue with contrasting changes in milk fat synthesis and lipogenic gene networks caused by lipid supplements. Funct. Integr. Genomics 10:561-575.

Kadegowda, A. K., M. Bionaz, L. S. Piperova, R. A. Erdman, and J. J. Loor. 2009. Peroxisome proliferator-activated receptor-gamma activation and long-chain fatty acids alter lipogenic gene networks in bovine mammary epithelial cells to various extents. J. Dairy Sci. 92:4276-4289.

Kadegowda, A. K., E. Connor, B. Teter, J. Sampugna, P. Delmonte, and L. Piperova. 2010. Dietary trans fatty acid isomers differ in 
their effects on mammary lipid metabolism as well as lipogenic gene expression in lactating mice. J. Nutr. 140:919-924.

Kairenius, P., A. Ärölä, H. Leskinen, V. Toivonen, S. Ahvenjärvi, A. Vanhatalo, P. Huhtanen, T. Hurme, J. M. Griinari, and K. J. Shingfield. 2015. Dietary fish oil supplements depress milk fat yield and alter milk fatty acid composition in lactating cows fed grass silage based diets. J. Dairy Sci. 98:5653-5671.

Lock, A. L., and D. E. Bauman. 2004. Modifying milk fat composition of dairy cows to enhance fatty acids beneficial to human health. Lipids 39:1197-1206.

Loor, J. J., M. Doreau, J. M. Chardigny, A. Ollier, J. L. Sebedio, and Y. Chilliard. 2005. Effects of ruminal or duodenal supply of fish oil on milk fat secretion and profiles of trans-fatty acids and conjugated linoleic acid isomers in dairy cows fed maize silage. Anim. Feed Sci. Technol. 119:227-246.

Ma, L., and B. A. Corl. 2012. Transcriptional regulation of lipid synthesis in bovine mammary epithelial cells by sterol regulatory element binding protein-1. J. Dairy Sci. 95:3743-3755.

Mach, N., A. A. A. Jacobs, L. Kruijt, J. van Baal, and M. A. Smits. 2011. Alteration of gene expression in mammary gland tissue of dairy cows in response to dietary unsaturated fatty acids. Animal $5: 1217-1230$.

Mozzon, M., N. G. Frega, B. Fronte, and M. Tocchini. 2002. Effect of dietary fish oil supplements on levels of n-3 polyunsaturated fatty acids, trans acids and conjugated linoleic acid in ewe milk. Food Technol. Biotechnol. 40:213-219.

Papadopoulos, G., C. Goulas, E. Apostolaki, and R. Abril. 2002. Effects of dietary supplements of algae, containing polyunsaturated fatty acids, on milk yield and the composition of milk products in dairy ewes. J. Dairy Res. 69:357-365.

Pawlak, M., P. Lefebvre, and B. Staels. 2015. Molecular mechanism of PPAR $\alpha$ action and its impact on lipid metabolism, inflammation and fibrosis in non-alcoholic fatty liver disease. J. Hepatol. 62:720-733.

Pierrot, N., D. Tyteca, L. D'auria, I. Dewachter, P. Gailly, A. Hendrickx, B. Tasiaux, L. E. Haylani, N. Muls, F. N'Kuli, A. Laquerrière, J. B. Demoulin, D. Campion, J. P. Brion, P. J. Courtoy, P. Kienlen-Campard, and J. N. Octave. 2013. Amyloid precursor protein controls cholesterol turnover needed for neuronal activity. EMBO Mol. Med. 5:608-625.

Pirondini, M., S. Colombini, M. Mele, L. Malagutti, L. Rapetti, G. Galassi, and G. M. Crovetto. 2015. Effect of dietary starch concentration and fish oil supplementation on milk yield and composition, diet digestibility, and methane emissions in lactating dairy cows. J. Dairy Sci. 98:357-372.

Reynolds, C. K., V. L. Cannon, and S. C. Loerch. 2006. Effects of forage source and supplementation with soybean and marine algal oil on milk fatty acid composition of ewes. Anim. Feed Sci. Technol. 131:333-357.

Salter, A. M. 2013. Dietary fatty acids and cardiovascular disease. Animal 7(Suppl. 1):163-171

Shingfield, K. J., S. Ahvenjärvi, V. Toivonen, A. Äröla, K. V. V. Nurmela, P. Huhtanen, and J. M. Griinari. 2003. Effect of dietary fish oil on biohydrogenation of fatty acids and milk fatty acid content in cows. Anim. Sci. 77:165-179.
Shingfield, K. J., L. Bernard, C. Leroux, and Y. Chilliard. 2010. Role of trans fatty acids in the nutritional regulation of mammary lipogenesis in ruminants. Animal 4:1140-1166.

Suárez-Vega, A., B. Gutiérrez-Gil, C. Klopp, C. Robert-Granie, G. Tosser-Klopp, and J. J. Arranz. 2015. Characterization and comparative analysis of the milk transcriptome in two dairy sheep breeds using RNA sequencing. Sci. Rep. 5:18399.

Suárez-Vega, A., P. G. Toral, B. Gutiérrez-Gil, G. Hervás, J. J. Arranz, and P. Frutos. 2017. Elucidating fish oil-induced milk fat depression in dairy sheep: Milk somatic cell transcriptome analysis. Sci. Rep. 7:45905.

Sukhija, P. S., and D. L. Palmquist. 1988. Rapid method for determination of total fatty-acid content and composition of feedstuffs and feces. J. Agric. Food Chem. 36:1202-1206.

Takeuchi, K., and K. Reue. 2009. Biochemistry, physiology, and genetics of GPAT, AGPAT, and lipin enzymes in triglyceride synthesis. Am. J. Physiol. Endocrinol. Metab. 296:E1195-E1209.

Ticiani, E., M. Urio, R. Ferreira, K. J. Harvatine, and D. E. De Oliveira. 2016. Transcriptional regulation of acetyl-CoA carboxylase $\alpha$ isoforms in dairy ewes during conjugated linoleic acid induced milk fat depression. Animal 10:1677-1683.

Toral, P. G., G. Hervás, A. Belenguer, D. Carreño, and P. Frutos. 2017. mRNA abundance of genes involved in mammary lipogenesis during fish oil- or trans-10, cis-12 CLA-induced milk fat depression in dairy ewes. J. Dairy Sci. 100:3182-3192.

Toral, P. G., G. Hervás, D. Carreño, A. Belenguer, and P. Frutos. 2015. Comparison of milk fatty acid responses during fish oil- and trans-10 cis-12 18:2-induced milk fat depression in dairy ewes. Anim. Feed Sci. Technol. 210:66-73.

Toral, P. G., G. Hervás, D. Carreño, and P. Frutos. 2016a. Does supplemental 18:0 alleviate fish oil-induced milk fat depression in dairy ewes? J. Dairy Sci. 99:1133-1144.

Toral, P. G., G. Hervás, A. Suárez-Vega, J. J. Arranz, and P. Frutos. 2016b. Isolation of RNA from milk somatic cells as an alternative to biopsies of mammary tissue for nutrigenomic studies in dairy ewes. J. Dairy Sci. 99:8461-8471.

Tsiplakou, E., and G. Zervas. 2013. Changes in milk and plasma fatty acid profile in response to fish and soybean oil supplementation in dairy sheep. J. Dairy Res. 80:205-213.

Vandesompele, J., K. De Preter, F. Pattyn, B. Poppe, N. Van Roy, A. De Paepe, and F. Speleman. 2002. Accurate normalization of realtime quantitative RT-PCR data by geometric averaging of multiple internal control genes. Genome Biology 3:RESEARCH0034.

Weimer, P. J., D. M. Stevenson, and D. R. Mertens. 2010. Shifts in bacterial community composition in the rumen of lactating dairy cows under milk fat-depressing conditions. J. Dairy Sci. 93:265278.

Zhu, J. J., J. Luo, Y. T. Sun, H. B. Shi, J. Li, M. Wu, K. Yu, A. B. Haile, and J. J. Loor. 2015. Short communication: Effect of inhibition of fatty acid synthase on triglyceride accumulation and effect on lipid metabolism genes in goat mammary epithelial cells. J. Dairy Sci. 98:3485-3491. 